\title{
The Economics of Road Network Ownership: An Agent-Based Approach
}

\author{
Lei Zhang ${ }^{1}$ and David Levinson ${ }^{2}$ \\ ${ }^{1}$ Department of Civil and Environmental Engineering, University of Maryland, \\ College Park, Maryland, USA \\ ${ }^{2}$ Department of Civil Engineering, University of Minnesota, Minneapolis, \\ Minnesota, USA
}

\begin{abstract}
This paper explores the economic impact of alternative ownership structures on transportation system performance, social welfare, and regulatory needs. Road pricing, investment, and ownership decisions are jointly considered in an agent-based evolutionary model applicable to large networks. Results suggest that a centralized public regime with average-cost pricing is far from socially optimal with even moderate demand growth. When properly regulated, a completely privatized transportation network could achieve net social benefits close to the theoretical optimum and distribute a high percentage of welfare gains to travelers. But an unregulated private road economy would suffer from higher-than-optimal tolls and overinvestment.
\end{abstract}

Key Words: network economics, privatization, road pricing, simulation of network evolution, transportation financing

\section{INTRODUCTION}

Whereas recent research in transportation economics has focused on the optimal pricing and investment strategies for road networks, a more fundamental economic issue-road network ownership that defines pricing and investment objectivesremains inadequately understood. The apparently important problem of identifying the optimal ownership structure given certain network supply and demand characteristics has not found a satisfactory solution. The ownership of a road

Received 29 August 2006; revised 5 October 2007; accepted 8 April 2008.

Address correspondence to Prof. David Levinson, Braun/CTS Chair in Transportation Engineering, Department of Civil Engineering, University of Minnesota, 500 Pillsbury Drive SE, Minneapolis, MN 55455, USA. E-mail: dlevinson@umn.edu 


\section{Zhang and D. Levinson}

network could be public or private, and centralized or decentralized, and it evolves over time. The presumption that prevailing transportation problems such as congestion and insufficient funding can be best resolved by the public sector is unwarranted and may produce less effective policies. A potentially more productive approach is to carefully examine theoretically sound and practically feasible road network ownership structures and to implement policies leading to the optimal regime, which could be private-centralized (monopoly), private-decentralized (competitive market), public-centralized (e.g., decisions made at the highest level of government or by large jurisdictions only), public-decentralized (e.g., decisions relegated to smaller jurisdictions), or an arrangement in between these extreme situations.

Previous research on road ownership has been experiential in nature. Authors have often based conclusions on the consequences of privatization in other economic sectors (Roth, 1996) or on empirical observations of the demand and cost characteristics of existing private roads (Gomez-Ibanez and Meyer, 1993). Winston and Shirley (1998) were able to quantify the welfare loss in urban transit systems due to inefficiencies inherent to public ownership but did not provide a model for analyzing road ownership. Theoretical studies on road ownership have focused on the pricing dynamics between private toll roads and public roads on small stylized networks (de Palma, 1992; Viton, 1995, Verhoef et al., 1996; de Palma and Lindsey, 2000). de Palma and Leruth (1989) and Yang et al. (2002) considered price and capacity competition in congested networks. Levinson (2000) examined price competition between serial monopolists with revenue-maximizing strategies. Verhoef and Rouwendal (2004) explored interrelations between pricing, capacity choice, and financing with a small-network model. Zhang and Levinson (2007) developed an analytical model of transportation network evolution and applied the model to study pricing dynamics and capacity decisions under alternative ownership structures. However, the equation systems provided in these theoretical analyses that capture economic decisions and user behaviors cannot be solved efficiently for real-world networks.

In contrast with the lack of large-scale road ownership models, private investment resources have already found several ways to enter real-world road systems. Although most roads in the United States are currently owned and operated by government agencies, an emerging trend is characterized by the development of new private toll roads (e.g., Denver E-470, Texas State Highway 130, The Dulles Greenway, San Diego SR125) and the private takeover/leasing of existing state-owned roads (e.g., Chicago Skyway, Indiana Turnpike). U.S. Department of Transportation 2006 statistics show that more than $50 \%$ of the current highway mega-projects ( $>500$ million investment) involve publicprivate partnerships. The advances in toll collection technology, needs for congestion relief, and increased use of alternative-fuel/hybrid vehicles have made road user charges (tolls, mileage fees, etc.) an increasingly attractive alternative to fuel taxes. This transition in revenue mechanism will likely cause a more decentralized road ownership structure in which private investors and smaller jurisdictions can participate in network pricing and investment practices. The issue of optimal road ownership is no longer a purely theoretical debate and bears practical importance. 


\section{Economics of Road Network Ownership}

This paper analyzes the economics of road network ownership and develops a quantitative model that evaluates the short- and long-run network performance under various ownership regimes. The performance measures include toll levels, network growth, investment returns, and social welfare. This research also makes several methodological contributions to network economics analysis. Different from the static game-theoretical formulations in most previous studies, a dynamic agent-based approach applicable to large networks is adopted to simulate road authorities' decisions and interdependencies. In particular, the profit-maximizing behavior of private roads is modeled as the result of an evolutionary learning process under imperfect information and uncertainty. Another uniqueness in our approach is the modeling of pricing-investment interdependencies at various decision points for both public and private roads, a consideration for historical dependencies in road networks. It is also recognized that private ownership structures often perform better from a society point of view when they are properly regulated. Therefore, the model is designed with the capability of assessing regulations on private roads. The agent-based approach for network analysis has been previously applied to model road pricing (Zhang and Levinson, 2005) and network capacity growth (Zhang and Levinson, 2003).

Although the proposed model structure can evaluate most mixed-ownership regimes in real-world networks, this paper considers a grid network for ease of interpretation and focuses on the comparison between a centralized public regime where all roads are controlled by a central government and a decentralized private regime where each road is an independent noncooperative profit-maximizing entity. Analyses of mixed-ownership regimes and ownership dynamics over time are left for future research. Neither the centralized public nor the decentralized private regimes are perfect from a rationality perspective. Under public ownership, the pricing decisions are constrained by political considerations and do not represent a first-best scheme. The public investment process pursues maximum welfare but is subject to revenue-neutral goals. Under private ownership, autonomous private roads have myopic expectations as they do not have perfect information about future user demand or their competitors' decisions.

Various considerations need to be addressed regarding the proper scope of private sector involvement in road infrastructure. Roads have monopoly power because they uniquely occupy space. Private roads may exercise their monopoly power and make socially undesirable pricing and investment decisions. There also exist barriers to market entry including the significant sunk cost of building new roads and the uncertain return on road investment especially when a competitor already exists. Also, equity and safety concerns are not necessarily consistent with the profit-maximizing objective of private investors, though the private sector has a reputational incentive to provide safe roads (Block, 1979, 1983). On the other hand, there are defendable benefits of a decentralized private ownership structure. Compared with government agencies with political objectives, private roads may be more willing to adopt innovative pricing schemes. Even though a market economy of private roads can result in high prices and excess profits in the short run, these price and profit signals in the long run will attract capital and entrepreneurs to the transportation sector, which could provide an effective solution to inadequate funding. The incentives for the private sector to minimize costs and provide 


\section{Zhang and D. Levinson}

efficient levels of service through innovation may change the supply curve of the industry and therefore benefit users. The quantitative evaluation framework developed in this paper is not comprehensive as it cannot entail all practical considerations. Rather, we suggest it be viewed as a valuable new tool that complements qualitative analysis of road ownership structures.

The remainder of the paper is organized as follows. Section 2 presents the agent-based network evolution model with an emphasis on travel demand and road supply characteristics. Section 3 models the interdependent pricing and investment strategies of public and private road authorities. When component models in Sections 2 and 3 are integrated, they are able to simulate the evolution of a road network under alternative ownership structures and provide detailed results regarding network performance, pricing dynamics, capacity growth, and social welfare over time with or without regulatory constraints. Section 4 demonstrates the model on a grid network under centralized public and decentralized private regimes. Section 5 summarizes the network simulation findings and discusses their policy implications. A price-ceiling regulation on private roads is also evaluated in this section. Conclusions are offered at the end of the paper.

\section{A MODEL OF NETWORK EVOLUTION}

An overview of model components and their interconnectivity is shown in Figure 1. Three aspects of the transportation system determine the path of network evolution: behavior, technology, and policy. A travel demand model captures the collective consequences of travelers' behavior and estimates traffic flows on individual links. All scenarios in the paper consider elastic travel demand with respect to time and toll. Road owners, public or private, invest toll revenues to defray road maintenance cost, build new capacity, and/or invest in other sectors of the economy. After each round of investment decisions, the transportation network may grow with expanded capacity or degenerate when not properly maintained, leading to supply-side changes. A new short-term traffic equilibrium is achieved every year in the model. If there is no overall travel demand growth, the network achieves a long-run supply-demand equilibrium when: (1) no user can reduce travel cost by unilaterally changing behavior; and (2) no private road owner can increase profit by unilaterally changing road toll or capacity subject to all applicable regulations; and (3) no public road authority can improve social welfare by unilaterally changing road toll or capacity subject to all applicable political constraints.

This section illustrates the demand and cost estimation procedures in the network model with the notation that follows below. Details of pricing and investment policies under alternative ownership structures are discussed in Section 4. It should be noted that users in the model are assumed to be homogenous with uniform values of time. Several recent studies show that ignoring user heterogeneity and the possibility of product differentiation may underestimate the benefits of road pricing and decentralized control (Cohen, 1987; Schmanske, 1993; Arnott et al., 1994; Daniel, 2001; Small and Yan, 2001; Verhoef and Small, 2004; Zhang et al., 2007). 


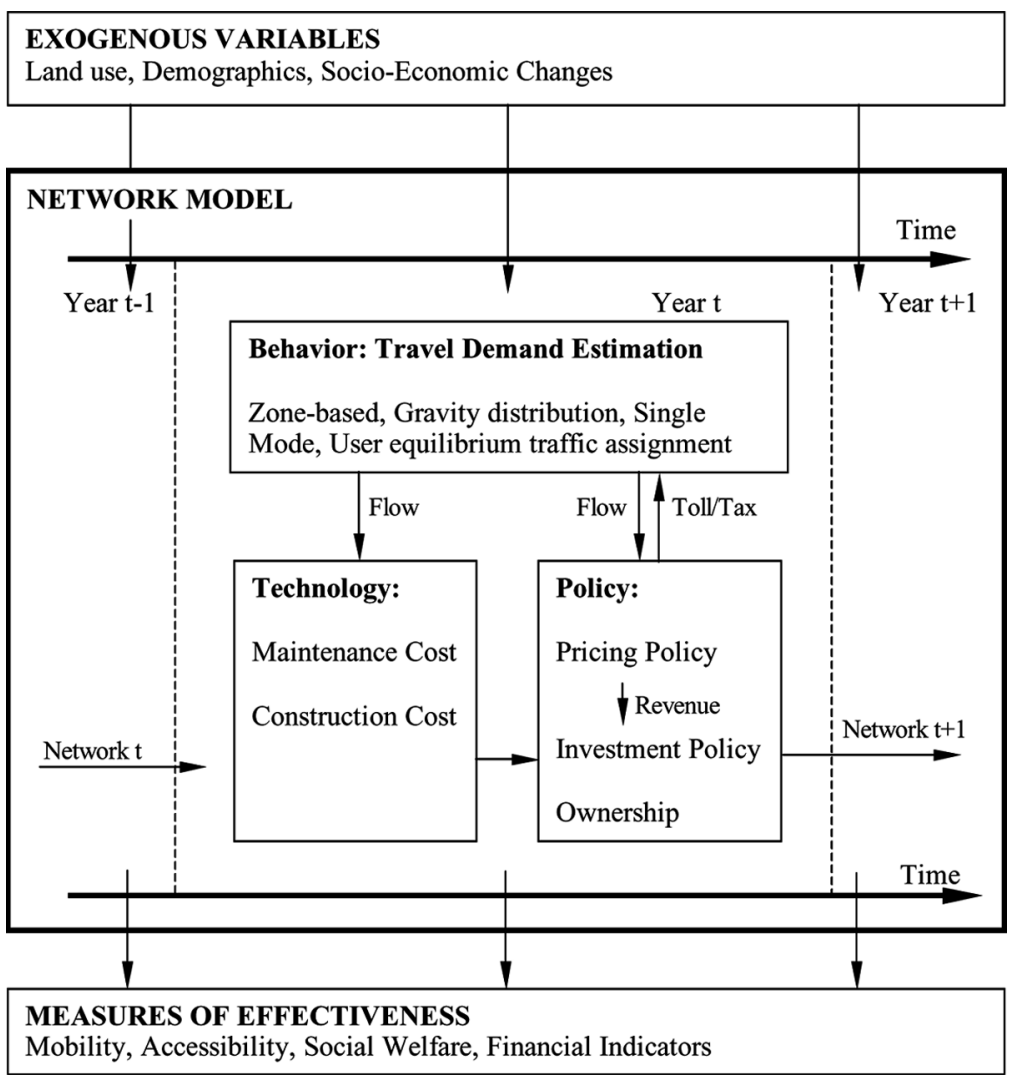

Figure 1. Flowchart of the simulation model.

$d(\cdot) \quad$ cost impedance function in the gravity model; $d\left(t_{r s}^{i}\right)=e^{-\gamma \cdot t_{r s}^{i}}$

$D_{s} \quad$ number of trips destined for zone $s$

$E_{a}^{i} \quad$ revenue (earnings) of link $a$ in year $i$ (dollar)

$K_{a}^{i} \quad$ cost of expanding link $a$ in year $i$ (dollar)

$f_{a}^{i} \quad$ average hourly flow on link $a$ in year $i$ (vehicles/hr)

$F_{a}^{i} \quad$ capacity of link $a$ in year $i$ (vehicles/hr)

$i \quad$ index of year

$j, k \quad$ parameters in the decentralized pricing model

$l_{a} \quad$ length of link $a$ (constant) $(\mathrm{km})$

$m_{n}, n_{s}$ coefficients in the gravity model

$M_{a}^{i} \quad$ cost of maintaining link $a$ in year $i$ (dollar)

$O_{r} \quad$ number of trips produced from zone $r$

$q_{r s}^{i} \quad$ demand from origin $r$ to destination $s$ in year $i$

$t_{a}^{i} \quad$ generalized travel cost on link a in year $i$

$t_{r s}^{i} \quad$ generalized travel cost from zone $r$ to $s$

$v_{a}^{i} \quad$ free-flow speed of link a $(\mathrm{km} / \mathrm{hr})$ in year $i$

$\alpha_{1-2} \quad$ coefficients in the maintenance cost function 


\section{Zhang and D. Levinson}

$\phi \quad$ scale parameter in the expansion cost function

$\gamma \quad$ coefficient in the impedance function

$\lambda \quad$ value of travel time (dollar/hr)

$\theta_{1-2} \quad$ coefficients of the BPR travel time function

$\rho \quad$ scale parameter in the centralized pricing model

$\sigma_{1-3} \quad$ coefficients in the expansion cost model

$\tau_{a}^{i} \quad$ link toll per vehicle defined in year $i$ (dollar; see equation 4 )

$\mu \quad$ scale parameter in maintenance cost function

$\pi_{1-2} \quad$ profit gains for private roads

$\omega_{1-2}$ coefficients in the capacity-speed model

$\psi \quad$ coefficient to scale hourly flows to annual flows

\subsection{Travel Demand}

We choose a traditional four-step model of travel demand because it has been calibrated and validated for many regions, recognizing that more advanced demand models are available (Kitamura, 1998; Boyce, 2002; Zhang and Levinson, 2004). The selected four-step model has a single mode (which we can think of as drive-alone), a zone-based regression structure for trip generation, a doubly constrained gravity model for trip distribution, and an origin-based user equilibrium traffic assignment algorithm (Bar-Gera and Boyce, 2003). The origin-destination (OD) cost table obtained from traffic assignment in year $i$ is used for trip distribution in year $i+1$ in the network simulation. The gravity model and the link travel cost function are specified in equations (1) and (2), respectively. Coefficients in the travel demand model are extracted from the Twin Cities metropolitan area planning model and summarized in Table 1.

$$
q_{r s}^{i}=m_{r} O_{r} n_{s} D_{s} \cdot d\left(t_{r s}^{i}\right)
$$

Table 1. Model coefficients.

\begin{tabular}{lcl}
\hline Parameter & Value & \multicolumn{1}{c}{ Source } \\
\hline$\lambda$ & 10 & Empirical finding \\
$\theta_{1}, \theta_{2}$ & $0.15,4$ & BPR Function \\
$\gamma$ & 0.1 & Empirical finding \\
$\rho$ & 0.005 & Scale parameter \\
$\psi$ & 3650 & Scale parameter \\
$\phi$ & 1 & Scale parameter \\
$\mu$ & 20 & Scale parameter \\
$\alpha_{1}$ & 1 & CRS of link length \\
$\alpha_{2}$ & 1.25 & DRS of capacity \\
$\sigma_{1}$ & 0.5 & Empirical finding \\
$\sigma_{2}$ & 1.25 & Empirical findings \\
$\sigma_{3}$ & 1 & CRS of additional capacity \\
$\omega_{1}, \omega_{2}$ & $-30.6,9.8$ & Empirical estimates \\
$k, j$ & $5,0.2$ & Link behavior assumptions \\
\hline
\end{tabular}

CRS: Constant Return to Scale; DRS: Decreasing Return to Scale. 


\section{Economics of Road Network Ownership}

$$
t_{a}^{i}=\lambda \frac{l_{a}}{v_{a}^{i}}\left[1+\theta_{1}\left(f_{a}^{i} / F_{a}^{i}\right)^{\theta_{2}}\right]+\tau_{a}^{i}
$$

\subsection{Cost Functions}

The functional forms for the cost functions are chosen based on project-level cost data collected in the Twin Cities metropolitan area in Minnesota (Levinson and Karamalaputi, 2003). The same data set is also used to estimate and validate the coefficients in the construction cost function.

The link maintenance cost function (using a Cobb-Douglas functional form) has two determining factors: link length and capacity. It costs more to maintain a link at its current level of service if the link is longer and carries heavier flow

$$
M_{a}^{i}=\mu \cdot\left(l_{a}\right)^{\alpha_{1}}\left(F_{a}^{i}\right)^{\alpha_{2}}
$$

There is limited empirical evidence on road maintenance cost at the individual link level. The bulk of the maintenance budget is typically spent on high-capacity roads (freeways and major arterials) due to their higher design standards and the reconstruction/rehabilitation needs of bridges and overpasses. Although there may be economies of scale in repaving roads, the existence of high-maintenance structures for high-capacity roads causes diseconomies of scale of maintenance cost with respect to link capacity $\left(\alpha_{2}>1\right)$. The current Cobb-Douglas maintenance cost model could be replaced with engineering cost models such as the one in the Highway Economic Requirement System (HERS).

Link expansion cost is considered a function of link length, existing link capacity, and the additional amount of capacity to be expanded:

$$
K_{a}^{i}=\phi \cdot\left(l_{a}\right)^{\sigma_{1}} \cdot\left(F_{a}^{i}\right)^{\sigma_{2}} \cdot\left(F_{a}^{i+1}-F_{a}^{i}\right)^{\sigma_{3}}
$$

In the empirical expansion cost model developed for the Twin Cities, Minnesota (Levinson and Karamalaputi, 2003), it is shown that construction cost has economies of scale with respect to the length of the road $\left(\sigma_{1}<1\right)$ and that it is more expensive to expand the same amount of capacity for higher-level high-capacity roads than for lower-level roads $\left(\sigma_{2}>1\right)$. Although the Twin Cities model suggests economies of scale with respect to additional link capacity, there has also been empirical evidence of increasing, constant, and decreasing returns to scale (Keeler and Small, 1977; Kraus, 1981; Newbery, 1989; Small et al., 1989; Levinson and Gillen, 1998; Small, 1999). The general consensus among transportation economists is that the marginal cost of an additional capacity unit is not far from constant, if it is not constant (Verhoef and Rouwendal, 2004). We therefore set $\sigma_{3}$ to be one in the model, which implies perfect self-financing in the socially optimal scenario, i.e., the amount of marginal cost toll revenue just recovers the construction cost. It should also be noted that capacity is treated as a discrete variable in the model; that is, capacity only increases with one or more additional lanes. 


\section{PRICING AND INVESTMENT POLICIES}

\subsection{Centralized Public Control}

Under centralized control, a government agency manages all roads, makes pricing decisions, and spends on road maintenance and construction based on a budget. This ownership scenario is constructed to approximately replicate the existing public road financing practices in the United States. Therefore, marginal cost pricing is not assumed. Interested readers may refer to Montes de Oca and Levinson (2006) for a detailed account of the network expansion decision-making process in the Twin Cities.

\subsubsection{Pricing Policy: Average Cost Pricing}

Under centralized control, users pay fuel taxes and registration fees for using the roads, which can be modeled as a distance-based charge when the variations in vehicle fuel efficiency are assumed away:

$$
\tau_{a}^{i}=\rho \cdot l_{a}
$$

This pricing equation represents an average-cost-pricing practice. Cost per kilometer of travel is the same no matter where or when trips occur. Revenue from each link is then collected, which is simply the product of the toll and annual traffic flow on the link:

$$
E_{a}^{i}=\tau_{a}^{i} \cdot\left(\psi \cdot f_{a}^{i}\right)
$$

where $\psi$ is a scale parameter that converts hourly flows to annual flows.

\subsubsection{Investment Policy: Benefit-Cost Analysis and Budget Balancing}

Revenues collected on all public roads are pooled together, and a central government agency makes all investment decisions. The public authority can always adjust the taxes so that the overall network revenue is higher than the cost for maintaining all links in the system. The remaining revenue after necessary maintenance activities is spent to expand road capacity according to benefit-cost analysis.

The maximum possible benefit/cost ratio $\left(B C_{\max }\right)$ of expanding a link, as well as the corresponding "optimal" amount of expansion $\left(\Delta F^{*}\right)$, is computed based on the construction cost function and the following assumptions: (1) Discount rate is $8 \%$; (2) the newly expanded capacity will produce benefits for 25 years; (3) only local (on the same link) travel time benefits are considered. Under these assumptions, the benefit/cost ratio becomes a single-variable convex function of the amount of capacity increase. $B C_{\max }$ and $\Delta F^{*}$ can then be analytically solved. The public road with the highest $B C_{\text {max }}$ is expanded first. The link with the next highest $B C_{\max }$ is then expanded, and so on until the revenue is exhausted. This implies that at the end of each year, the centralized government agency has a balanced budget with no deficit or surplus. Obviously, it is possible for this budget-balancing invest policy to cause underinvestment or overinvestment in the network. However, this nonoptimal investment model is consistent with current public financing practices that seek revenue-neutral goals. 


\section{Economics of Road Network Ownership}

When roads are expanded, the capacity increase is usually associated with a concurrent change of free-flow speed. For instance, free-flow speeds on higher-capacity roads such as divided arterials and freeways are higher than those of lower-capacity roads. This positive correlation is estimated with speed and capacity data used by the Twin Cities Metropolitan Council in their regional planning models on more than 10,000 roadway sections. A parsimonious log-linear model provides the best goodness-of-fit:

$$
v_{a}^{i}=\omega_{1}+\omega_{2} \cdot \ln \left(F_{a}^{i}\right)
$$

\subsection{Decentralized Private Control and Regulation of Private Roads}

\subsubsection{Pricing Policy: Short-Run Profit-Maximizing}

When setting tolls, private roads under decentralized ownership take road capacity as given and seek to maximize their short-run profits in an imperfectly competitive market. This analysis does not adopt a game-theoretic approach to compute profit-maximizing prices because obtaining the Nash-type equilibrium solutions would be computationally difficulty (if possible at all) on large networks and require strong simplifying assumptions about the availability of current/future information. In a market economy consisting of many private roads, any individual private investor does not possess perfect knowledge about other investors' road pricing and capacity expansion decisions, which causes uncertainty about the demand curves on individual private roads.

We alternatively model private roads' profit-maximizing pricing behavior as the outcome of an adaptive learning process. In this approach, a private link in the network copes with uncertainty and imperfect information by learning demand patterns from historical road usage data under road tolls set in the past. The collective influence of the decisions by other private roads is represented by the shape of the link-specific demand curve (i.e., link flow versus generalized link travel cost). The process through which the private link adjusts its toll to maximize profit is depicted in Figure 2. Due to traffic growth and/or new pricing/investment decisions by other links, the demand curve on the private link shifts over time. Therefore in each time period, the private link estimates a new demand curve based on its own link flows and tolls in the previous $k$ time periods (represented by crosses in the graph) with linear line-fitting techniques. The $k$ previous tolls fall into a range $\left[P_{\text {low }}, P_{\text {High }}\right]$. The estimated demand curve can be extrapolated beyond this toll range (the dashed portions on the demand curve). Based on this empirical demand curve learned from experience, a standard quadratic optimization procedure finds the theoretical profit-maximizing toll, $P^{*}$, for the next time period. If $P^{*} \in\left[P_{\text {low }}, P_{\text {High }}\right]$ (case A in Fig. 2), it is directly implemented as new toll. However, if $P^{*}$ is in a new price territory (case $\mathrm{B}$ ), the link will take caution and adjust its toll toward $P_{B}^{*}$ only by a conservative small step $j$ to $P_{\text {Low }}(1-j)$, where $j$ is a parameter. Similarly, if $P_{B}^{*}$ is higher than $P_{\text {High }}$ (not shown in Fig. 2), the new toll would be $P_{\text {High }}(1+j)$.

This pricing rule assists private roads to maximize profit and keep the price changes smooth. It should be a plausible pricing rule when the uncertainty about future travel demand abounds. For instance, the private road toll on 


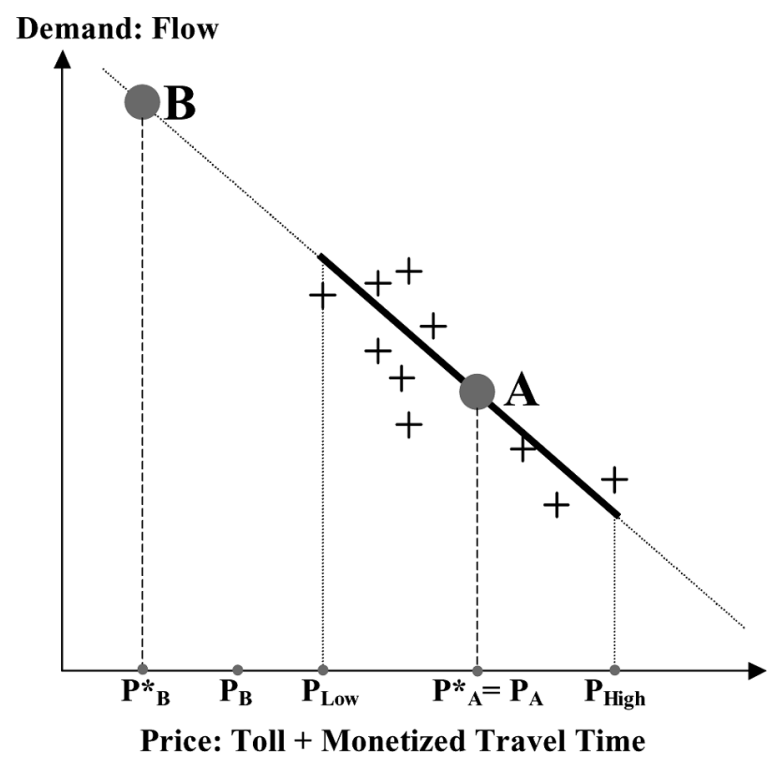

Figure 2. Profit-maximizing pricing under uncertainty.

the Dulles Greenway has been adjusted up and down several times due to unexpected demand conditions (FHWA, 2006). Computationally, this learningbased adaptive pricing policy can be efficiently executed on networks with a large number of links. The impact of toll regulations can also be easily incorporated, as we shall see later in the paper when a price-ceiling regulation is introduced. However, the heuristic nature of this adaptive pricing rule may introduce estimation biases when demand curves shift abruptly or consistently in the same direction for a long period of time. Future research should both explore the theoretically optimal pricing strategy for private roads under uncertainty and analyze the real-world pricing practices of existing toll-road operators.

\subsubsection{Investment Rule: Long-Run Profit-Maximizing}

Capacity expansion allows private links to increase revenue by charging higher tolls, attracting more traffic, or both at the expense of expansion and additional maintenance costs. If the rate of investment return is higher than the discount rate, a private link should expand its capacity with toll revenue or by borrowing from other investors. Otherwise, the private link should invest toll revenue elsewhere. These investment options for private roads are made possible in our model by a bank agent. The bank agent pays interest for savings and upon request lends money to links with potentially profitable capacity expansion projects.

While the life-cycle cost of private road expansion can be computed from cost functions, the additional toll revenue from the added capacity depends on the traffic growth rate and other links' economic decisions. The following procedure 


\section{Economics of Road Network Ownership}

estimates the expected profit from capacity expansion with consideration of uncertainty and imperfect information:

1. Assume the current link demand curve will not change significantly during the life cycle of the capacity expansion project.

2. Compute travel time reductions for users under all feasible discrete capacity expansion scenarios (e.g., adding one or two more lanes).

3. Apply the link demand curve to estimate the increased amount of traffic with reduced travel time and unchanged toll. Calculate the amount of profit gain during the project life cycle due to the increased link traffic, $\pi_{1}$.

4. Convert an average user's time saving on the link following capacity expansion to a monetary value $\Delta \tau$. Increase the link toll by $\Delta \tau$, which should keep traffic flow unchanged. Compute the profit gain during the project life cycle due to the higher link toll, $\pi_{2}$.

5. The final estimated profit gain is the maximum of $\pi_{1}$ and $\pi_{2}$.

The rationale behind this profit estimation procedure is as follows. The extra profit with added capacity results from increased traffic and/or increased toll. The above procedure finds the profit gains when either one of those two profit sources is completely exploited. Future research should examine the possibility of exploiting both sources at once, which should produce even higher estimates of profit gains. Assumption (1) is a simplification. More intelligent private road operators may better adjust their capacities and anticipate likely future demand curve shifts according to past observations.

The profit-maximizing pricing and investment strategies modeled in this section are hybrid strategies based on heuristic rules, learning, and optimization principles. The simulation results presented in Section 5 later in the paper show that these hybrid strategies serve the profit-maximizing objective very well. For instance, private roads on the test network are able to keep more than $75 \%$ of total welfare gains as their profits when there is no regulation.

\subsubsection{Regulation on Private Roads}

As discussed in the introduction, private roads possess spatial monopoly power and will likely charge higher-than-optimal tolls on their users, leading to welfare losses. In addition, market entry barriers due to high construction cost and demand uncertainty imply that the private road economy is not a perfect market. Therefore, comparing a centralized public ownership with an unregulated private ownership is not fair because in theory, proper regulations on private roads can improve welfare. There are various types of regulations on private roads, with price ceiling, fixed profit, cap on rate-of-return, and shadow tolls being the most popular (FHWA, 2006). Limited by the length of the paper, we will only consider the price ceiling regulation in which a global maximum toll level (e.g., $\$ 3$ per $\mathrm{km}$ ) is set for all private roads.

For any regulatory policy, there is also the issue of optimal regulation. In the case of price ceiling, the optimal ceiling price that maximizes social welfare needs to be determined so that the full potential of the regulation can be appreciated. When the ceiling price is too high, its influence on private roads' pricing and investment decisions is marginal. When it is too low, private roads may not be 


\section{Zhang and D. Levinson}

willing to expand an under-built network to the optimal capacity level. We identify the optimal ceiling price by simulating a large number of alternative ceiling prices (i.e., from $\$ 0$ to $\$ 10$ per $\mathrm{km}$ in $\$ 0.1$ increments) and evaluating the corresponding welfare measures. Although a global ceiling price for all links is assumed herein for simplicity, the optimal ceiling price in theory could vary on a link-by-link basis.

\subsection{Socially Optimal Pricing and Investment Policies}

A socially optimal scenario is included in the analysis to estimate the maximum possible welfare and serve as a benchmark. Overall social welfare or net social benefit consists of consumers' surplus and suppliers' surplus. Changes in consumers' surplus are computed using the "rule of half" (Neuburger, 1971) under the assumption of a linear demand curve. Annual toll revenue after the amortized expansion and maintenance costs are subtracted provides an estimate of suppliers' surplus or profit. The optimal pricing policy in a first-best environment is marginal cost pricing, which is estimated by the link travel time savings when a single user is removed from the link. It should be noted the true system-wide marginal cost of an additional trip can be different from the local link-level marginal cost (Safirova and Gillingham, 2003). The capacity of a link is at optimum if the marginal cost of building one extra unit of capacity just equals the marginal benefit. The socially optimal investment policy defined herein is similar to the public investment strategy described in Section 3.1.2 except that the budget balancing constraint is removed. When there is still residual revenue after all capacity expansion projects with rates of investment return larger than the discount rate have been implemented, the residual revenue is saved (presumably allocated to other more desirable public investment projects) rather than invested inefficiently for additional capacity expansion. In this optimal scenario, the public road authority may also allocate funds from outside the transportation system to socially desirable capacity expansion projects when toll revenues are insufficient.

\section{DESCRIPTION OF SIMULATION EXPERIMENTS}

The network evolution model is readily applicable to large real-world networks. The amount of time required to run the model for a single time period is slightly longer than what is required to run a traditional four-step model. A $10 \times 10$ grid network (100 nodes and 360 links) is used in this paper to explore the consequences of alternative ownership structures for ease of interpretation (e.g., the effect of spatial monopoly is easier to observe on a grid network than on an irregular real-world network). Each link in the grid network is 3.2-km long and has an initial capacity of 735 vehicles/hour (this value corresponds with the capacity of the average one-lane road according to a regression analysis using the capacity and number-of-lane data in the Twin Cities regional planning model). The initial network is moderately congested with an average volume/capacity ratio of 0.8. The initial land use is uniform among all 100 zones (each node is also a zone centroid) with 10,000 trips originating from and destined for each zone. Although the use of a grid network loses to a real-world network on realism and the immediate applicability of research findings, it wins on the elimination of confounding and conflating factors and the convenience of running a large 


\section{Economics of Road Network Ownership}

number of scenarios within a relatively short amount of time. But it should be noted that the OD demand matrix for a grid network where short trips are more frequent than long trips may not adequately represent the demand patterns in certain real-world cities. In some cases, a circular city network would be more realistic than the rectangular grid employed in our simulation experiments.

Two sets of simulation experiments are conducted. The first set assumes no overall travel demand growth (referred to as the no-growth scenario hereafter). The long-term supply-demand equilibrium can be achieved in this case when all equilibrium conditions listed at the beginning of Section 2 are satisfied. The second set of experiments assumes the overall network travel demand increases at an annual rate of $3 \%$ (the growth scenario, i.e., $O_{r}$ and $D_{s}$ in equation (1) increase uniformly across all zones by $3 \%$ every year). With demand growth, the road network would continuously evolve over time without achieving an equilibrium state. The same initial network condition is specified for all simulation scenarios. Four experiments are conducted for each demand growth scenario: (1) centralized public regime; (2) decentralized private regime without regulation; (3) decentralized private regime with price-ceiling regulation; and (4) socially optimal.

\section{RESULTS}

\subsection{The No-Growth Scenario}

It should be noted again that even in the no-growth scenario, the demand curves for individual links still shift over time. Figure 3 plots the link tolls and capacities after the long-run supply-demand equilibria are achieved. The marginal-cost tolls are higher on links in the center of the grid as they attract more traffic and have higher levels of congestion than do links on the edges. The socially optimal capacity distribution is quite (though not perfectly) flat, which is largely explained by the assumed uniform land-use pattern in all zones. Under centralized control, we can observe capacities significantly lower than the optimum levels. Apparently, when the average-cost price implemented as distance-based tolls or fuel taxes is lower than the optimal marginal-cost price (which is the case in congested networks), it cannot generate sufficient revenues for all desirable network capacity expansions. Quantitative analysis of network evolution under decentralized control has not been available previously. It is therefore interesting to examine the last two graphs in Figure 3. The profit-maximizing capacity is almost the same as the optimal capacity on the edges of the network, and overinvestment can be observed in the center. The higher level of competition among the central links accounts for their higher-than-optimal capacity. On the other hand, tolls are higher in the decentralized private regime, which should reduce traffic volumes and hence the benefit from capacity expansion in terms of congestion relief. The difference between regimes in investment levels is the net effect of these opposing forces. The imperfection of the private road economy is exemplified in the equilibrium toll graphs in Figure 3. The spatial monopoly power of roads is evident and most obvious on the edge and corner links where travelers have fewer or no choices for service. These links are able to maximize profits by charging very high tolls with 


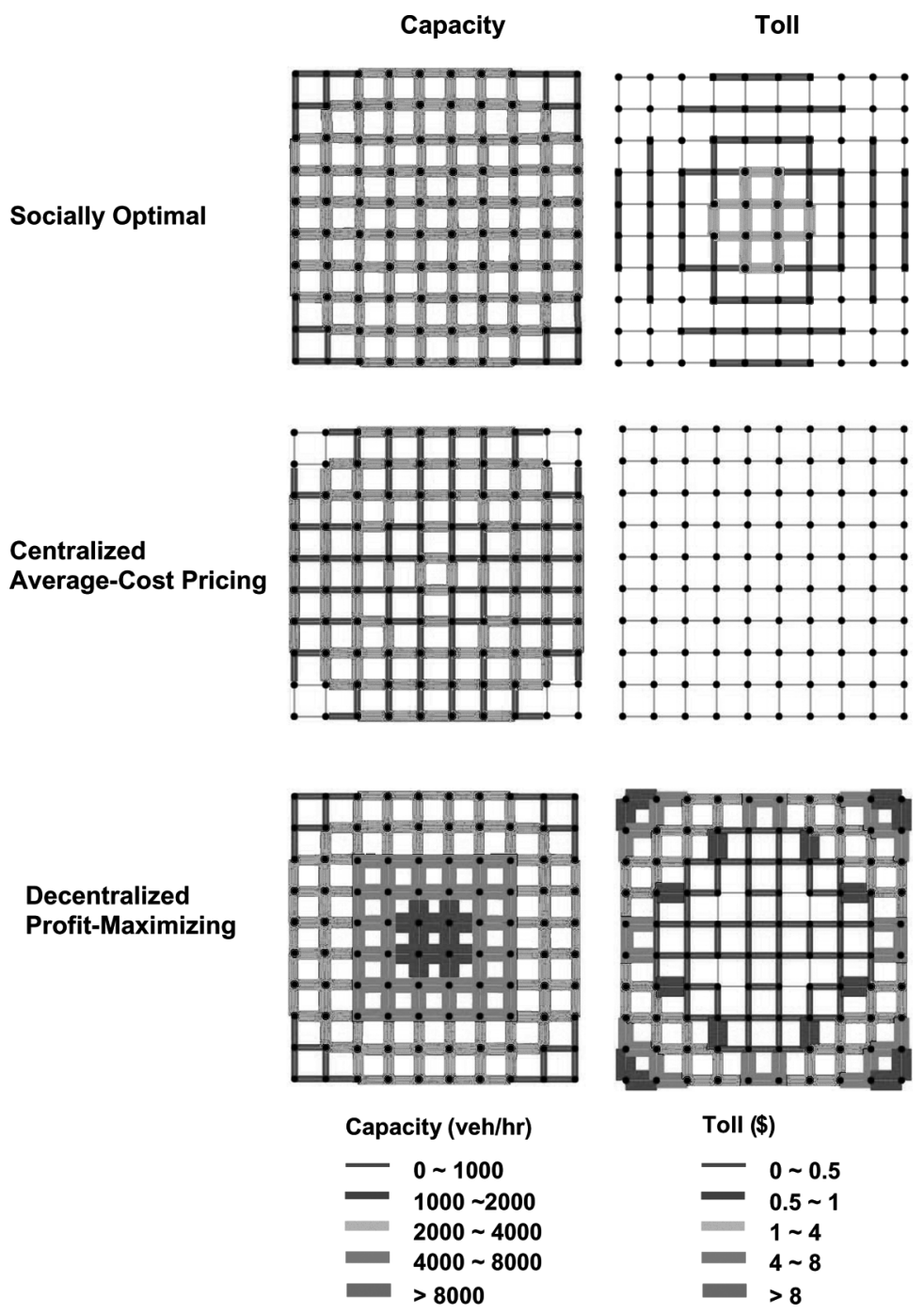

Figure 3. Equilibrium tolls and capacity in the no-growth scenario.

minimum capacity expansion. For the central links, competition forces them to charge tolls closer to the marginal congestion cost.

Figure 4 presents key measures of network effectiveness over time. An evolutionary analysis of the equilibration process provides a unique opportunity to examine the strengths and weaknesses of specific ownership structures. While the socially optimal and centralized control scenarios quickly achieve stable equilibria after a few years, the decentralized control cases take much longer time to converge. Because the initial network is congested, the marginal congestion tolls are very high in the beginning. The resulting abundance of toll revenue then allows road capacities to be quickly expanded to their optimal levels within several years. 
Net Social Benefit (M\$)

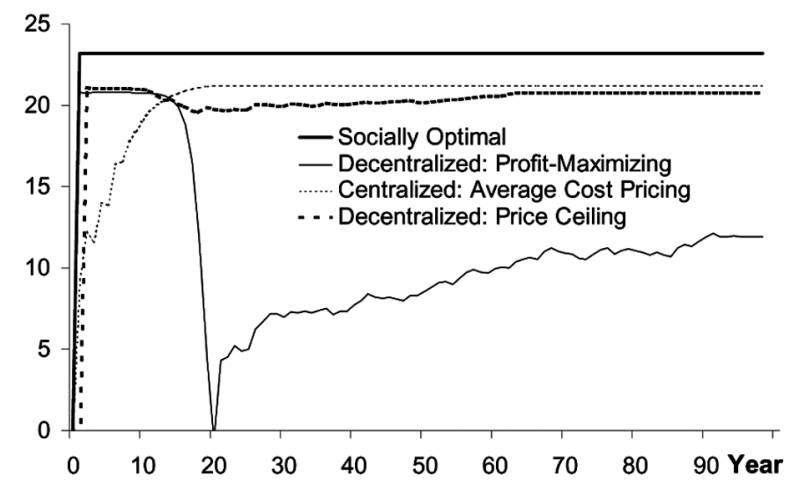

Average Toll (\$)

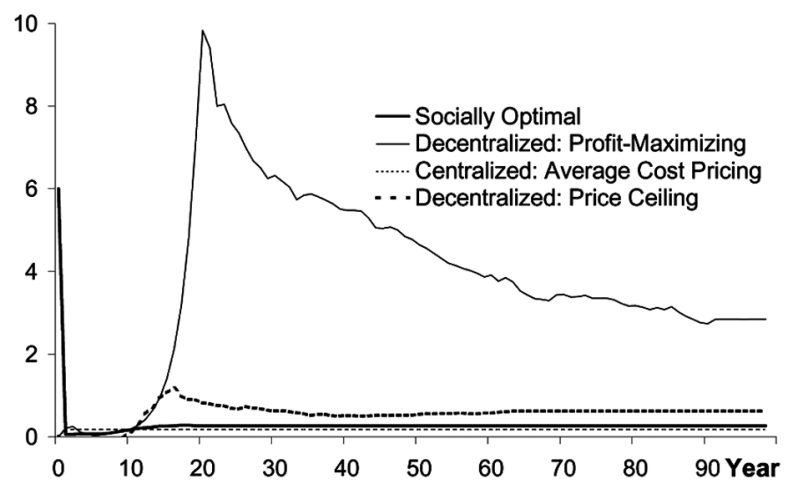

\section{Cumulative Number of Capacity Expansion Projects}

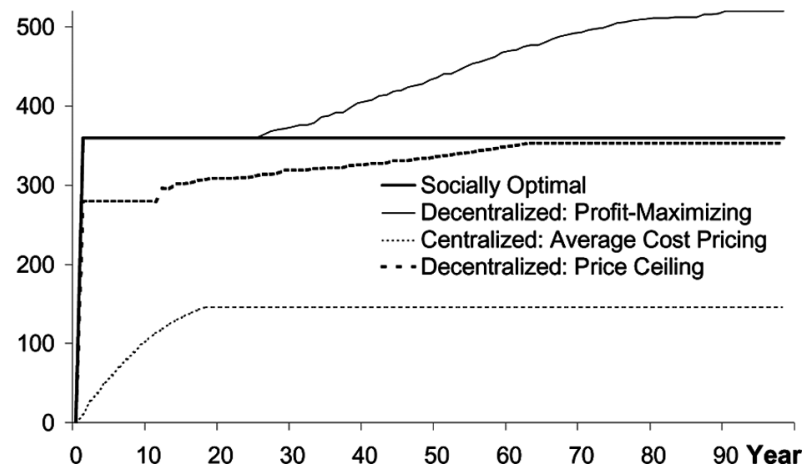

Figure 4. Network evolution in the no-growth scenario.

The centralized control scenario displays slow responses to congestion but eventually achieves a net social benefit about $85 \%$ of the maximum possible. The issue of under-built capacity under centralized control is evident in the graph plotting the cumulative number of capacity expansion projects (i.e., number of times the 


\section{Zhang and D. Levinson}

links in the network are expanded). The pricing and investment behavior of private roads in the decentralized road economy are almost identical to the socially optimal case during the first 10 years. Observing congestion and the opportunity to increase profit by capacity expansion, they immediately borrow from investors to expand network capacity to a nearly socially optimal level. However, they gradually learn the profitability of higher tolls under no regulation. High tolls bring significant profits that pay off loans. The residual profits are not immediately reinvested in the transportation system until after year 25. Road users suffer from high tolls. Net social benefit drops to almost zero in year 20 when the average private road toll peaks. Eventually, competition in the network among private roads leads to steady toll reductions. The average private road toll finally stabilizes around $\$ 2.85$ per link (or $\$ 0.89$ per $\mathrm{km}$ ).

The above equilibrium and evolutionary analyses clearly show that the inefficiencies of the unregulated private regime result from higher-than-optimal tolls and subsequent overinvestment in capacity. The following section summarizes the role of price-ceiling regulations in preventing these socially inefficient outcomes.

\subsection{The Role of Regulation}

If we compare the curves under the private regimes with and without regulation in Figure 4, it is clear that the optimal ceiling price is very effective in preventing high tolls and overinvestment. Figure 5 illustrates the influence of various global ceiling prices on net social benefit, consumers' surplus, and private road profit. The socially optimal ceiling price is about $\$ 2.0$ per $\mathrm{km}$. At this ceiling price, the net social benefit is about $84 \%$ of the maximum possible and rivals that under centralized control $(85 \%)$. In addition, the percentage of net social benefit attributable to consumers' surplus is about $83 \%$ when the optimal ceiling price is adopted. Because these findings are based on a simple regulatory scheme, it is reasonable to believe that more sophisticated regulation schemes (e.g., link-specific ceiling tolls)

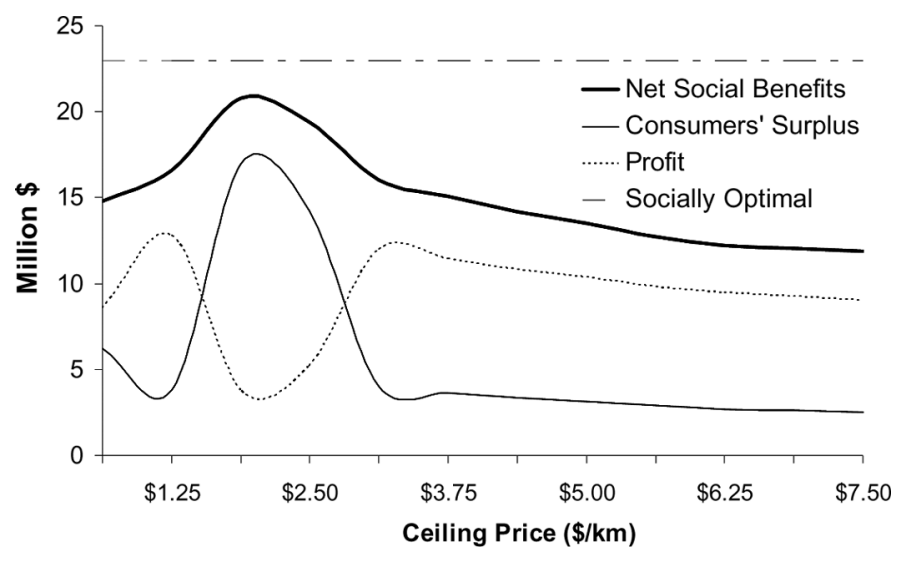

Figure 5. Determination of the optimal ceiling price. 


\section{Economics of Road Network Ownership}

would allow the decentralized private regime to outperform the centralized public regime.

A somewhat unexpected observation is that profit for private roads appears to be a bimodal function of the ceiling price with two local maxima on the test network. This deserves further discussion. When ceiling prices are low $(<\$ 1.2 / \mathrm{km})$, private roads do not have incentives to expand capacities toward the optimal levels. Consequently, as the ceiling price increases within this low range, they simply raise tolls to gain more profit, which leads to the first local profit maximum. When the ceiling price continues to increase above $\$ 1.2 / \mathrm{km}$, the noncooperative competition among private roads forces them to build more capacity but only charge moderate tolls (as constrained by the moderate ceiling price). Profit therefore decreases to a minimum at the $\$ 2.0 / \mathrm{km}$ ceiling price. When the ceiling price becomes higher than $\$ 2.0 / \mathrm{km}$, private tolls continue to increase at the higher capacity level, leading to the second local profit maximum at the $\$ 3.5 / \mathrm{km}$ ceiling price. This finding on the complexity of the profit-maximizing problem for private roads in a market economy suggests that the same level of profit can be achieved at multiple toll rates. An implication is that in order to capture the highest possible profit, private roads may need to probe the market periodically by adjusting their tolls.

\subsection{The Growth Scenario}

Travel demand in many urban areas has been increasing at a fast pace over the past several decades, and this trend is likely to continue in the foreseeable future. Therefore from a practical point of view, it is more relevant to evaluate network performance in the growth scenario than in the no-growth scenario. Simulation experiments in the growth scenario reveal how well the public and private ownership regimes can handle rapidly changing demand conditions. Figure 6 presents the evolutionary paths of the grid network under the two alternative ownership regimes. Apparently, the network will not achieve an equilibrium in the growth scenario.

The problems associated with the centralized public regime, namely suboptimal prices and insufficient revenue for capacity expansion that we have already observed in the no-growth scenario, get worse with demand growth. If the current public funding level continues into the future, the centralized public road network would exhibit disappointing performance even worse than that of a decentralized private network without any regulation. These findings on the test network favor private-sector involvements in network financing in rapidly growing areas.

The responsiveness of private roads to changing demand conditions is a major benefit under decentralized control. Though earlier-than-optimal investment occurs around year 15 due to high tolls and hence higher expected returns on capacity investment, the total capacity expansion projects, measured by the cumulative number of times links have already been expanded, are not far from the optimal level most of the time. A small price spike can still be observed in the private market economy between years 15 and 30. However, the average link toll under the private control overlaps with the socially optimal tolls for a significant period of time. 


\section{Zhang and D. Levinson}
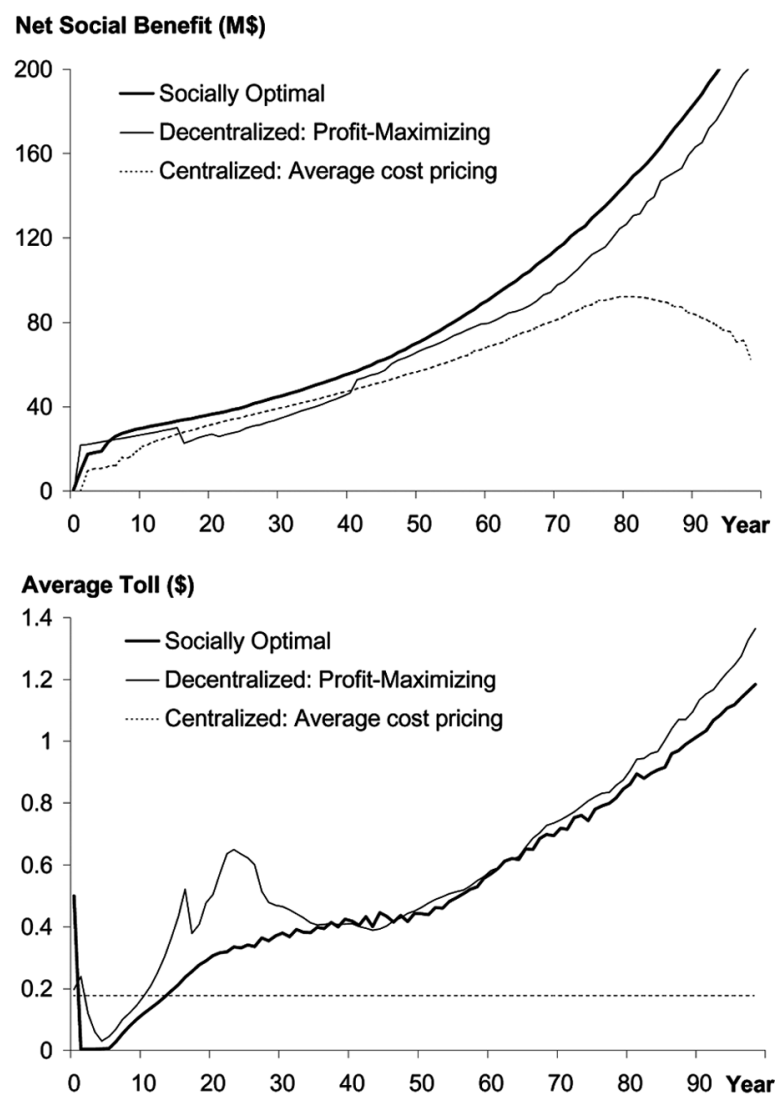

Cumulative Number of Capacity Expansion Projects

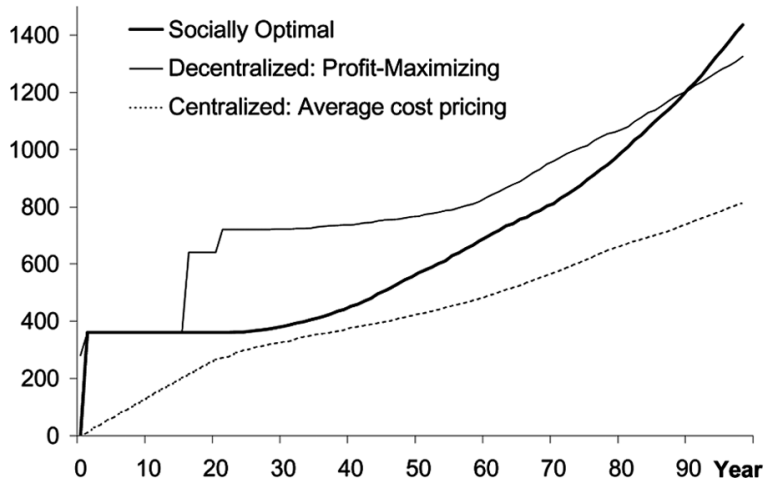

Figure 6. Network evolution in the growth scenario.

\section{CONGLUSIONS}

This research develops an agent-based model to study the welfare consequences of alternative ownership policies for road networks. The evolution of a transportation network consisting of profit-maximizing private roads in a market economy is 


\section{Economics of Road Network Ownership}

analyzed and modeled. The paper jointly considers pricing schemes, investment strategies, and ownership structures in an integrated analytical framework applicable to large networks, which has not been studied despite its obvious policy significance. Discussions of road privatization and its various consequences have long been conducted at the theoretical and conceptual levels. The quantitative approach for road ownership analysis developed herein provides a valuable analytical method and complements the qualitative approaches.

Findings from a grid network should encourage those in favor of a marketoriented approach to solving urban transportation problems. However, the goal of profit-maximization, the existence of spatial monopoly, complex interdependencies, and severe competition could all cause private roads in a market economy to adopt socially nonoptimal tolls and capacities. Yet, even a rudimentary price-ceiling regulation is shown to be capable of overcoming many of the drawbacks of a decentralized private regime. Private roads in a market economy are particularly robust in areas with increasing travel demand. These conclusions should be tested by future studies on real-world urban road networks.

One limitation of the research is that users are assumed to be homogenous with the same value of time. This could affect the results in two ways. Disregarding user heterogeneity prohibits analysis of certain equity impacts on users, and equity is an important part of social welfare. It also prevents product differentiation in the transportation network and generally causes underestimation of total welfare in a market economy. Another limitation is that cooperation among private roads is assumed away. There may be advantages to both the private and social welfare if vertical integration of highly complementary links is allowed in the system. However the degree of complementarity for which integration serves both public and private interests remains to be determined. The questions of when and how a link seeks coalitions at the microscopic level and how road network evolves with changing ownership structures need to be answered. However, it would be interesting to observe in future research what kind of organizational structure will emerge in a market economy to take advantage of the economies of scale in the network. Other interesting extensions for future research include simulating mixed publicprivate ownership structures and comparing a Nash-type equilibrium and the simulation model outcome on a stylized network.

\section{ACKNOWLEDGMENTS}

The authors would like to thank the guest editor and an anonymous reviewer for their thorough technical and editorial comments on the paper. The Kiewit Center for Infrastructure and Transportation at the Oregon State University has provided partial financial support for this research. The authors are solely responsible for all statements in this paper.

\section{REFERENGES}

Arnott R, de Palma A, Lindsey R. 1994. The welfare effects of congestion tolls with heterogeneous commuters. Journal of Transport Economics and Policy 28(2):139-161. 


\section{Zhang and D. Levinson}

Bar-Gera H, Boyce D. 2003. Origin-based algorithm for combined travel forecasting models. Transportation Research 37B(5):405-422.

Block W. 1979. Free market transportation: Denationalizing the roads. Journal of Libertarian Studies 3(2):209-238.

Block W. 1983. Theories of highway safety. Transportation Research Record 912:7-10.

Boyce DE. 2002. Is the sequential travel forecasting paradigm counterproductive? Journal of Urban Planning and Development 128(4):169-183.

Cohen Y. 1987. Commuter welfare under peak-period congestion tolls: Who gains and who loses? International Journal of Transport Economics 14(3):238-266.

Daniel JI. 2001. Distributional effects of airport congestion pricing. Journal of Urban Economics 50:230-258.

de Palma A. 1992. A game-theoretic approach to the analysis of simple congested networks. American Economic Review 82(2):494-500.

de Palma A, Leruth L. 1989. Congestion and game in capacity: A duopoly analysis in the presence of network externalities. Annales D'Économie et de Statistique 15/16:389-407.

de Palma A, Lindsey R. 2000. Private toll roads: Competition under various ownership regimes. Annals of Regional Science 34:13-35.

FHWA (Federal Highway Administration). 2006. Public-private partnerships case studies. Available at: http://www.fhwa.dot.gov/ppp/case_studies.htm. Accessed October 30, 2006.

Gómez-Ibáñez J, Meyer J. 1993. Going private: The international experience with transport privatization. Washington, DC: Brookings Institute.

Keeler TE, Small KA. 1977. Optimal peak-load pricing, investment and service levels on urban expressways. Journal of Political Economy 85:1-25.

Kitamura R. 1988. An evaluation of activity-based travel analysis. Transportation 15:9-34.

Kraus M. 1981. Scale economies analysis for urban highway networks. Journal of Urban Economics 9:1-22.

Levinson D. 2000. Revenue choice on a serial network. Journal of Transport Economics and Policy 34(1):69-98.

Levinson D, Gillen D. 1998. The full cost of intercity highway transportation. Transportation Research 3D:207-223.

Levinson D, Karamalaputi R. 2003. Induced supply: A model of highway network expansion at the microscopic level. Journal of Transport Economics and Policy 37(3):297-318.

Montes de Oca N, Levinson D. 2006. Network expansion decision making in Minnesota's twin cities. Transportation Research Board: Transportation Research Record 1981:1-11.

Neuburger H. 1971. User benefits in the evaluation of transport and land-use plans. Journal of Transport Economics and Policy 5(1):52-75.

Newbery DM. 1989. Cost recovery from optimally designed roads. Economica 56:165-185.

Roth G. 1996. Roads in market economy. Aldershot, OK: Avebury.

Safirova EA, Gillingham KT. 2003. Measuring marginal congestion costs of urban transportation: Do networks matter? Discussion Paper 03-56. Washington, DC: Resources for the Future.

Schmanske A. 1993. A simulation of price discriminating tolls. Journal of Transport Economics and Policy 27:225-235.

Small KA. 1999. Economies of scale and self-financing rules with non-competitive factor markets. Journal of Public Economics 74:431-450.

Small KA, Winston CM, Evans CA. 1989. Road work. Washington, DC: Brookings Institution.

Small KA, Yan J. 2001. The value of "value pricing" of roads: Second-best pricing and product differentiation. Journal of Urban Economics 49:310-336.

Verhoef ET, Nijkamp P, Rietveld P. 1996. Second-best congestion pricing: The case of an untolled alternative. Journal of Urban Economics 40:279-302. 


\section{Economics of Road Network Ownership}

Verhoef ET, Rouwendal J. 2004. Pricing, capacity choice, and financing in transportation networks. Journal of Regional Science 44(3):405-435.

Verhoef ET, Small KA. 2004. Product differentiation on roads: Constrained congestion pricing with heterogeneous users. Journal of Transport Economics and Policy 38(1):127-156.

Viton PA. 1995. Private roads. Journal of Urban Economics 37:260-289.

Winston C, Shirley C. 1998. Alternate route: Toward efficient urban transportation. Washington, DC: The Brookings Institution.

Yang H, Tang WH, Cheung WM, Meng Q. 2002. Profitability and welfare gain of private toll roads in a network with heterogeneous users. Transportation Research 36A:537-554.

Zhang L, Levinson D. 2003. A model of the rise and fall of roads. Presented at the 50th North American Regional Science Council Annual Meeting, Nov. 20-22, Philadelphia, PA.

Zhang L. Levinson D. 2004. Agent-based approach to travel demand forecasting: Exploratory analysis. Transportation Research Record: Journal of the Transportation Research Board 1898:28-36.

Zhang L, Levinson D. 2005. Road pricing with autonomous links. Transportation Research Record: Journal of the Transportation Research Board 1932:147-155.

Zhang L, Levinson D. 2007. The economics of transportation network growth. In: Coto P, Vicente I (eds.), Essays on transportation economics. New York: Springer Science, pp. 317-339.

Zhang L, Zhu S, Levinson D. 2008. Agent-based model of price competition, capacity choice, and product differentiation on congested networks. Journal of Transport Economics and Policy 42(3):435-461. 